\title{
ТОM \\ Decisions to choose genetically modified foods: how do people's perceptions of science and scientists affect their choices?
}

\section{Jiyoun Kim and Sumin Fang}

\begin{abstract}
This study explores the effects of food science perception on food decisions in the controversial case of genetically modified (GM) foods. We examine (1) how scientific consensus and scientific deference affect the public perception of GM foods; and (2) how perception and healthy eating interest influence people's actual food consumption decisions. We categorized our samples into four groups based on different risk/benefit perceptions of GM food: tradeoff, relaxed, skeptical, and uninterested in the process of further data analysis.
\end{abstract}

Keywords

Health communication; Public perception of science and technology; Public understanding of science and technology

https://doi.org/10.22323/2.19020201

Submitted: 17 th July 2019

Accepted: 24th February 2020

Published: 16th March 2020

Healthy eating has received more attention from the public in recent decades [Barry et al., 2011; Kim and Anne Willis, 2007]. Although it seems that food options in the market continue to increase and people are more interested in healthy eating than ever before, it is not clear if people are actually making healthier food choices [Funk and Kennedy, 2016a]. People in the U.S. seek health benefits from making better food choices; however, most people are still confused about what foods to eat and what foods to avoid, which makes them doubt their choices [Food Insight, 2017].

Genetically modified (GM) foods, which are the products of food science, have long been controversial and have a history of complicating people's food-related decisions. GM foods contain genetically modified organisms that change the natural DNA to obtain new traits [Wunderlich and Gatto, 2015]. GM crops have surged during the past two decades. For instance, the Statista's 2019 report noted that about $94 \%$ of the total soybean crops in the United States were genetically modified in 2019 [Shahbandeh, 2019]. Although GM crops have been widely adopted in the U.S. and other regions, about two thirds of Americans do not actively follow news about GM foods [Funk and Kennedy, 2016a]. They use mass media and the Internet as primary sources of information about it [Wunderlich and 
Gatto, 2015]. Starting in 2020, the United States Department of Agriculture (USDA) will require foods with GM ingredients to self-identify with labels so the public can be better informed about GM foods.

Despite the advantages of GM food and assurances from scientists and officials that GM food science is safe [Funk, Rainie and Page, 2015], the public continues to express concerns about the potential risks for personal health, food safety, and the environment [Bawa and Anilakumar, 2013; Costa-Font, Gil and Traill, 2008; Domingo and Giné Bordonaba, 2011]. In Turker et al.'s [2013] study, more than 70\% of respondents indicated that consuming GM food is dangerous. Due to perceived risks of genetically modified foods, many people find it hard to make a decision about if they should consume or abstain from genetically modified foods.

Considering that every behavior involves choices [Ajzen, 2015; Ajzen, 1991; Ajzen, 1985], this study focuses on what drives people to make decisions about food science. Using this controversial topic of accepting or avoiding genetically modified foods as a context of inquiry, this study explores how people's perceptions of science and scientists impact their GM food attitudes and how people's perceptions of GM foods interact with their desire to eat healthy foods to influence decisions about GM food consumption.

\section{Scientific consensus on public perception and decision}

Although existing studies have suggested that people's scientific knowledge impacts their attitudes towards GM food [e.g. Wunderlich and Gatto, 2015], people's scientific knowledge does not necessarily reflect their perception and acceptance of the technology. In the process of making decisions about controversial food technologies, researchers note that members of the public can make decisions without ample relevant scientific knowledge. The cognitive miser model supports the idea that people tend to seek less information but use more heuristic shortcuts to form attitudes toward a complex issue in an effort to save on cognitive capacity [Fiske and Taylor, 1991]. Popkin [1994] also argued that people would not exert extra effort to seek information about an issue unless there are rewards for such behaviors. Considering that most Americans have a limited understanding of scientific research [American Academy of Arts \& Sciences, 2018], we expect that information shortcuts (e.g., attitudes toward scientists and perceptions of scientific findings) can play heuristic roles on people's decisions on the issue. Existing studies provide empirical evidence supporting our assumption. For instance, in Eden's [2011] study, participants showed more willingness to apply scientists' views of GM food in their decision making if they held favorable perceptions of scientists and scientific findings.

Researchers observed that the public's uncertainty about food science originated from their concerns about scientific dissonance regarding biotechnologies in the food industry. More specifically, the differing opinions among scientists about functional foods have created public confusion [Eden, 2011]. If the public doubts whether scientists have reached consensus about the safety of controversial technology, they tend to show hesitation in their acceptance of it [Flipse and Osseweijer, 2013; Jensen and Hurley, 2012; Marques, Critchley and Walshe, 2015]. The Gateway Belief Model, a psychological theory of how public attitudes and judgments are formed on scientific issues [Maibach and van der Linden, 2016; van der Linden, Leiserowitz, Feinberg et al., 2015; van der Linden, Clarke and Maibach, 
2015; van der Linden, Leiserowitz and Maibach, 2019], also stresses the role of scientific consensus on public perception and acceptance of technology. The theoretical model assumes that messages presenting scientific consensus serve as the "gateways" for persuading public opinion about controversial issues to further strengthen public support for behavioral changes that scientists suggest. In van der Linden et al.'s [2015] study, consensus messages about climate change significantly increased people's perceptions of the scientific support for this issue, which then impacted their agreement about human responsibility for this phenomenon. Perceived scientific consensus, in van der Linden et al.'s [2015] study, eventually increased support for public action to fight against climate change. Based on these arguments, we posit the following hypotheses:

H1: Perceived scientific consensus about GM food safety will be associated with favorable perception of GM foods.

H2: Perceived scientific consensus about GM food safety will positively be associated with GM food consumption.

\section{Public views on scientists as moderators}

Scientific consensus is critical for public acceptance, but it is not necessarily equally effective for everyone. For example, scientific consensus messages on vaccination and autism were only effective among participants who self-reported high deference to scientific authorities [Dixon et al., 2015; van der Linden, Clarke and Maibach, 2015]. Hence, in addition to perceived scientific consensus on controversial scientific issues, public attitudes towards the scientific community (e.g., deference to scientific authority in Brossard and Nisbet's [2007] and Dixon's [2016] studies; trust in scientists in Besley and Shanahan's [2005] study) has also been considered one of the vital variables in predicting public perceptions and attitudes on scientific issues.

Research shows that people rely on their trust in science and technology as a shortcut to reduce uncertainties and replace their own proactive efforts in seeking information on these issues [Critchley, 2008; Siegrist, 2000]. In Vandermoere et al.'s [2011] study, public knowledge of controversial scientific issues was not necessarily associated with positive perceptions of it. Instead, the people with more trust in science and technology tended to show more support for the technology. Similarly, Siegrist [2000] found that trust in science and technology institutions working on gene technologies was positively correlated with perceived benefits about the technologies and negatively associated with perceived risks. Furthermore, trust in scientific communities was eventually positively associated with acceptance of the gene technologies. When it comes to GM foods, trust in scientists directly correlates to positive public attitudes toward the technology [Marques, Critchley and Walshe, 2015]. Therefore, we are interested in exploring the influence of public attitudes towards the scientific community on public perception of GM foods. In particular, this study concerns if people's deference to scientific authority moderate the effect of scientific consensus and public perceptions of GM foods.

H3: Public views on scientists should differentially interact with scientific consensus to affect GM food perception: Higher levels of deference to scientific authority will strengthen the positive relationship between scientific consensus and favorable perception of GM foods compared to people with lower levels of deference to scientific authority. 
Perception of controversial foods on food decisions
When adopting controversial technology, people try to understand its implications before making decisions on the issue. As known, laypeople evaluate the issue as risks versus benefits [Knight, 2007]. As previously discussed, however, unlike scientists' favorable attitudes toward GM foods, the public continues to be critical of GM foods [Funk, Rainie and Page, 2015] because of their complexity. Public perception of GM food remains controversial because people are concerned about its unknown potentially harmful effects on health and the environment [Bawa and Anilakumar, 2013; Domingo and Giné Bordonaba, 2011; Yang and Chen, 2016]. Members of the public seem concerned that effects of GM foods on human health are not yet fully understood [Frewer et al., 2004], and worry that scientists have failed to provide long-term effects of the technology, which fuels the public's feeling of uncertainty about whether scientists have obtained a full picture of GM foods [Barrows, Sexton and Zilberman, 2014].

According to Brossard and her colleagues [2009], public perceptions of controversial technology operate as interpretative frameworks in making decisions. Several studies found that public perception had significant influences on people's acceptance or rejection of emerging technologies [e.g. Akin et al., 2018; Cacciatore, Scheufele and Corley, 2011; Kim, Yeo et al., 2014]. People show higher acceptance levels of technologies when they perceive more benefits [Siegrist, 2000], but they show less support if they perceive more risks [Dunwoody and Neuwirth, 1991; Slovic, 1999]. When an issue appears to have potential risks, perceived risk is associated with opposition or rejection, because risks are thought to be unknown [Slovic, 1987] and perceived uncertainty affects peoples' risk acceptability [Slovic, Fischhoff and Lichtenstein, 1982].

In the context of food decisions - whether to consume a certain food - favorable public perception toward a specific food positively affects consumption. On the other hand, when the public takes a negative stance on certain foods, it negatively affects consumption [Turker et al., 2013]. Not surprisingly, people showed stronger doubt about food safety when they were skeptical about GM foods [Kikulwe, Wesseler and Falck-Zepeda, 2011] and tended to avoid GM foods if they were concerned about the potential risks [Bawa and Anilakumar, 2013; Domingo and Giné Bordonaba, 2011]. Hence, this study assumes that public's favorable perception of GM foods plays a key role in predicting their actual GM food decisions. In other words, supporters and opponents of GM foods tend to base their opinions on how they perceive the food technology. We posit the following hypothesis:

H4: Favorable perception of GM foods will be positively associated with GM food consumption.

\section{The moderating role of healthy eating interest}

Despite the influence of positive and negative perceptions, people's behavior may vary depending on situational conditions. In the context of food decisions, although this study assumes that people's food perceptions impact their food choice intentions, there is still no easy way to predict people's actual behavior.

Some scholars [e.g. Miller, 2001; Regan and Fazio, 1977] have highlighted the influence of self-interest as a determinant in predicting people's behavior on certain 
issues. In the context of food choice, existing studies [Gil, 2000; Hasimu, Marchesini and Canavari, 2017; Niva, 2007] found that personal interest in healthy diets had considerable influence on food decisions. It seems people are more interested in healthy eating than ever before, because it has been thought that people's food choices affect their health [Funk and Kennedy, 2016a]. The United States Department of Agriculture [2016] stated that making healthy food choices provides health benefits, including a reduced risk of some chronic diseases. Although healthy eating is increasingly popular, not everyone reacts in the same way to the issues. For example, compared to people with low levels of health consciousness, people with high levels of health consciousness are more responsive to health information as reflected in their behavior changes [Dutta-Bergman, 2006] and are more likely to engage in activities believed to confer good health [Iversen and Kraft, 2006]. Indeed, previous research shows that people's interests in pursuing healthy diets were the most salient value motivating their food purchases [Hughner et al., 2007; Rana and Paul, 2017].

When it comes to healthy food decisions, fruits and vegetables seem to be representative healthy foods, but it has long been controversial to consider GM foods as healthy foods. The public attitude towards GM foods indicates that there are many concerns about its potential risks for personal health, food safety, and the environment [e.g. Costa-Font, Gil and Traill, 2008; Domingo and Giné Bordonaba, 2011]. In particular, Bawa and Anilakumar [2013] pointed out that some laypeople believe that consuming GM foods can cause human disease and may increase resistance to antibiotics. As a result, people tend to avoid GM foods if they are interested in personal health and healthy diets [Lü, 2006; Turker et al., 2013]. Hence, it is reasonable to expect that people's healthy eating interests might moderate the relationship between food perception and food science decisions. Therefore, we propose the following hypothesis:

H5: People's healthy eating interests will moderate the relationship between their perception and consumption of GM foods.

Combining all of the possible effects, this study proposes the conceptual research model shown in Figure 1.

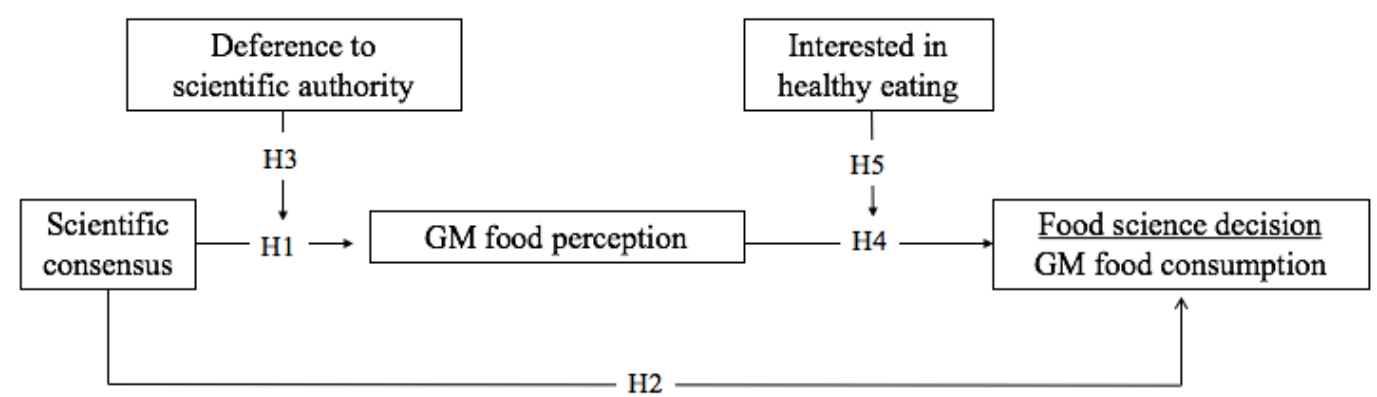

Figure 1. Hypothetical model of this study. 
The different audiences of GM food decisions
As previously discussed, this study focuses primarily on how favorable perception of GM foods influences consumption decisions. However, it is complicated to predict people's food behavior, because most Americans have mixed views on GM foods and acknowledge that there are both benefits and risks of GM foods [Funk and Kennedy, 2016b].

Based on deliberate reasoning [Eagly and Chaiken, 1993], Kim and his colleagues [2013] stated that some people, particularly scientifically well-informed people, make rational judgments about GM foods after consciously calculating the potential risks and benefits. However, Kim et al. also argued that people who tend to minimize their cognitive efforts to seek necessary information when forming an opinion (i.e., cognitive misers) use cognitive shortcuts or rules of thumb to make quick judgments about scientific controversies. Gaskell et al. [2004] argued that some people perceive both risks and benefits for GM foods and try to balance out these attributes to make rational decisions on the issue (e.g., evaluating if the benefits outweigh the risks or vice versa) while others rely on one attribute - either risk or benefit perception - to make a simple judgment. Therefore, this study proposes two research questions concerning whether people choose different strategies when making decisions about controversial GM food science.

RQ1: Do people choose a rational choice model (making tradeoffs between risks and benefits) or rules of thumb (taking either risks or benefits as shortcuts) when making a decision to consume GM foods?

RQ2: Depending on benefit and risk perception, do people rely on different degrees of influence regarding scientific consensus, perceptions of GM food, and healthy eating interests to make their GM food consumption decisions?

Methods

In order to test our hypotheses, this study uses a secondary data from the American Trends Panel (ATP) Wave 17 survey for the Pew Research Center, which was collected by Abt SRBI. The survey was administered in English and Spanish. The PEW Research Center collected data from national, probability-based online panel, and in total, 4,563 members completed the survey ${ }^{1}$ (age 18 and over, residing in the U.S.) from May 10 to June 6, 2016. However, this study relied only on a subset of respondents $(n=1480)$ as this group was specifically queried about healthy eating interest and GM food consumption.

\section{Measures}

Dependent variable. This study explores what influenced peoples' GM food consumption decision. GM food consumption was measured on a single 4-point scale item ( $1=$ None at all; $4=$ Most of it): "How much of the food you eat has genetically modified ingredients?" $(M=2.45, S D=0.90)$.

Independent and moderating variables. This study measured perceived scientific consensus variable to explore the main and interactive influences of public views on scientist on food perception and decision. Perceived scientific consensus about GM food safety was measured with one 5-point item (1=Almost

\footnotetext{
${ }^{1}$ Web respondents $\mathrm{N}=4,091$; Mail respondents $\mathrm{N}=472$.
} 
none; $5=$ Almost all): "How many scientists say that genetically modified foods are safe to eat?". $(M=3.28, S D=1.13)$. Deference to scientific authority — as an index of public views on scientists - was measured as a moderating variable with one 4-point item (1=Not at all well; 4=Very well): "How well do scientists understand the health risks and benefits of eating genetically modified foods?". $(M=2.77, S D=$ $0.83)$.

In prediction of actual food choice, i.e., GM food consumption in the current study, this study puts favorable perception of GM foods as independent variable.

Favorable perception of GM foods was measure with one 3-point item "Do you think foods with genetically modified ingredients are generally worse for your health than foods with no genetically modified ingredients (1); neither better nor worse for your health than foods with no genetically modified ingredients (2); or better for your health than foods with no genetically modified ingredients (3)". $(M=1.69$, $S D=0.64)$.

To test the interactive influences of GM food perceptions on food consumption decision, healthy eating interest was measured with one 4-point item (1=Not at all; $4=$ Very well): "In my overall approach to eating, my main focus is on eating healthy and nutritious". $(M=2.89, S D=0.72)$.

Control variables. Socio-demographic: in order to control possible unintended influence on food consumption decision, this study controls four socio-demographic variables: age, which was categorized into a four point scale $(1=18-29 ; 2=30-49 ; 3=50-64 ; 4=$ above $65, M=2.45, S D=1.03)$, gender (52.5 percent females), education, which was an ordinal variable measured with 6 categories (1=less than high school; $2=$ high school; $3=$ =some college, no degree; $4=$ Associate's degree; $5=$ College graduate/some postgrad; $6=$ Postgraduate, $M=3.34, S D=1.56$ ), and household income was an measured with 3 ordinal categories (1=Less than $\$ 30,000 ; 2=\$ 30,000-\$ 74,999 ; 3=$ more than $\$ 75,000)$.

\section{The categorization of respondents (RQ1E2)}

Gaskell et al. [2004] introduced risk-benefit analysis to predict people's judgment about GM food. To determine whether different groups applied different decision rules, Gaskell et al. used two dimensions - perceived risks and perceived benefits of GM foods - to categorize participants into four groups: tradeoff (useful and risky), relaxed (useful and not risky), skeptical (not useful and risky), and uninterested (not useful and not risky). The results suggested that the different groups might weigh risks and benefits in different ways when making judgments about the issue of GM foods. Similar to Gaskell et al.'s [2004] study, during the data analysis process, we categorized our participants into four groups that reflected different levels of risk and benefit perception: Group 1: Tradeoff — Perceive both benefits and risks of GM foods; Group 2: Relaxed - Perceive GM foods as useful and not risky; Group 3: Skeptical - Perceive GM foods as not useful and high risk; and Group 4: Uninterested - Perceive neither benefit nor risk.

We assessed benefits using a four-point scale that ranged from very likely to not at all likely in response to the following question: "How likely it is that genetically modified foods will lead to more affordably priced food?" $(M=2.67, S D=0.92)$ 
Using the same 4-point scale, we assessed risk by taking the average of participants' responses to the following a question: "How likely is it that genetically modified foods will lead to health problems for the population as a whole?" $(M=2.56, S D=0.88)$

\section{Methodological notes}

To test (a) the influence of scientific consensus on GM food perception and (b) main and interactive effects of GM food perception on actual food consumption choice, the current study uses hierarchical ordinary least squares (OLS) regression models. In particular, to find the predictors' relative explanatory variances, this study enters independent variables into blocks based on possible causal order. Interaction terms were created in order to assess the degree to which moderators amplified or attenuated influence on the peoples' food perception and choice. To avoid issues of multicollinearity between an interaction term and its component, each of the interaction terms was constructed by multiplying the standardized value of each main effect variables [Cohen and Cohen, 1983]. In the process of data analyses, potential confounding effects of respondent demographics were controlled. Sample is weighted using population parameters from the U.S. Census Bureau to compensate for any potential sampling biases.

This study focuses on how perceived scientific consensus about GM food safety directly (H1) and interactively (H3) play roles in people's perception of GM foods. To test research hypotheses, this study constructed hierarchical regression models to examine the effects. As demonstrated in Table 1, as expected, the results show that people who perceive higher scientific consensus tend to show a more favorable perception of GM foods (H1: $\beta=.25, \mathrm{p}<.001)$. Hence, H1 was supported.

When it comes to the moderating role of public views on scientists in the influence of scientific consensus about food safety on favorable perception of GM foods (H3), the current study found statistical evidences that perceived scientific consensus and people's deference to scientific authority simultaneously affect GM food perceptions in a positive way $(\mathrm{H} 3: \beta=.15, \mathrm{p}<.001)$. In detail, as can be seen in Figure 2, the interaction reveals that among individuals who appear more deference to scientific authority, those who perceive higher scientific consensus about GM foods safety were much more likely to have a favorable perception of GM foods than those who perceive lower scientific consensus. Among the group of individuals who were less deference to scientific authority, however, there was attenuated difference in the effect of scientific consensus on GM food perception. So, H3 was also supported.

This study also explores the factors affecting people's GMO food decision - i.e., GMO food consumption (H2, H4 \& H5). To test the research hypotheses, this study ran a hierarchical regression model. As shown in Table 2, our data showed that people tend to consume more GM foods when they perceive more scientific consensus that GM foods are safe to eat $(\mathrm{H} 2: \beta=.25, \mathrm{p}<.001)$. Thus, $\mathrm{H} 2$ was supported. The current study also hypothesized that when people have more 
Table 1. Regression predicting GM food perception.

\begin{tabular}{|c|c|}
\hline & $\begin{array}{l}\text { Favorable perception of GM food } \\
\qquad(\mathrm{N}=1368)\end{array}$ \\
\hline \multicolumn{2}{|l|}{ Block 1: Demographic (Control) } \\
\hline Age & .02 \\
\hline Gender & -.01 \\
\hline Education & $-.18^{* * *}$ \\
\hline Household Income & .03 \\
\hline Incremental $\bar{R}^{2}$ & $2.2 \%$ \\
\hline \multicolumn{2}{|l|}{ Block 2: IV } \\
\hline Scientific consensus & $.25^{* * *}$ \\
\hline Incremental $R^{2}$ & $6.9 \% * * *$ \\
\hline \multicolumn{2}{|l|}{ Block 3: Moderator } \\
\hline Deference to scientific authority & $.06^{* * *}$ \\
\hline Incremental $R^{2}$ & $0.3 \% * * *$ \\
\hline \multicolumn{2}{|l|}{ Block 4: Interaction } \\
\hline Scientific consensus $\times$ Scientific deference & $.15^{* * *}$ \\
\hline Incremental $\bar{R}^{2}$ & $2 . \overline{\%}^{* * *}$ \\
\hline Total $R^{2}$ & $11.8 \% * * *$ \\
\hline
\end{tabular}

Note: Cell entries are final standardized regression coefficients.

a) The variable gender was coded $0=$ male, $1=$ female; $b){ }^{*} \mathrm{p}<.05 ;{ }^{* *} \mathrm{p}<.01 ; * * * \mathrm{p}<.001$.

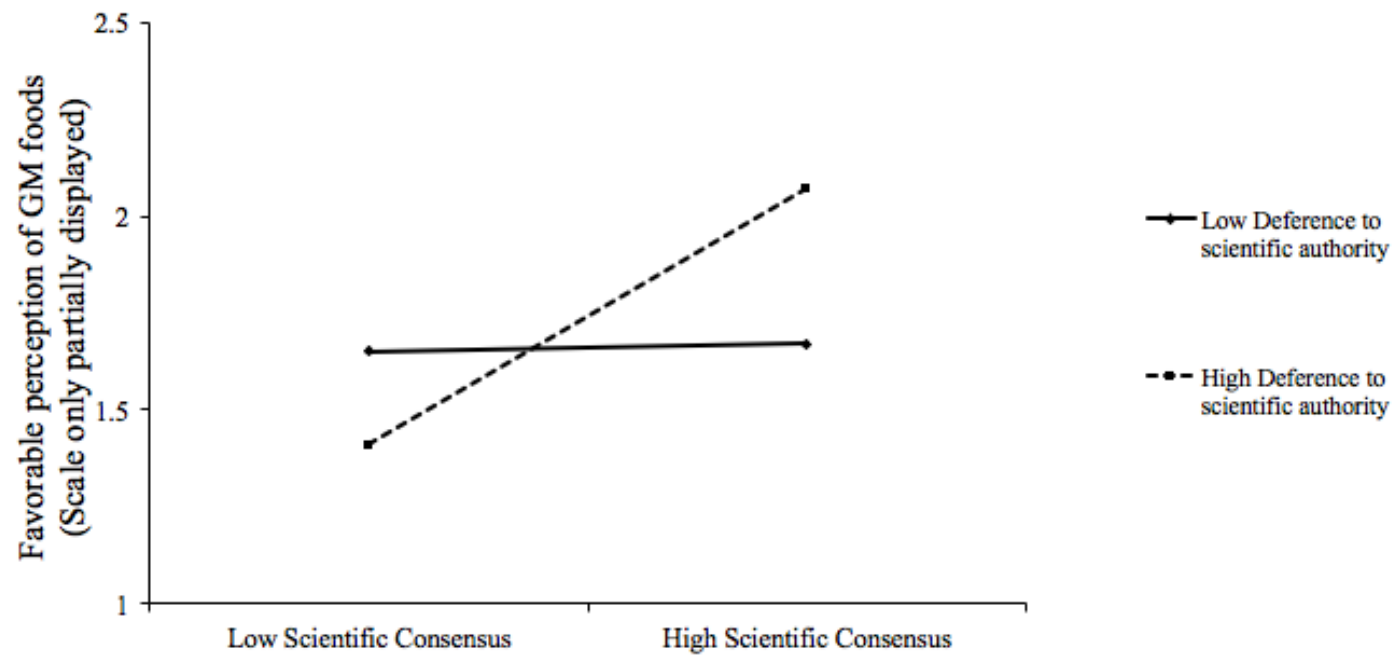

Figure 2. Interaction effect between perceived scientific consensus and deference to scientific authority on GM food perception.

favorable perception of GM foods, they would consume more GM foods (H4). However, this study failed to find a significant main effect of GM food perception on consumption decision (H4: $\beta=-.02, p=n . s)$. So, $\mathrm{H} 4$ was not supported.

This study also sought to analyze the moderating role of healthy eating interest in the influence of favorable perception on GM food consumption (H5). As expected, this study found significant evidence that individuals' healthy eating interests 
Table 2. Regression predicting GM foods consumption.

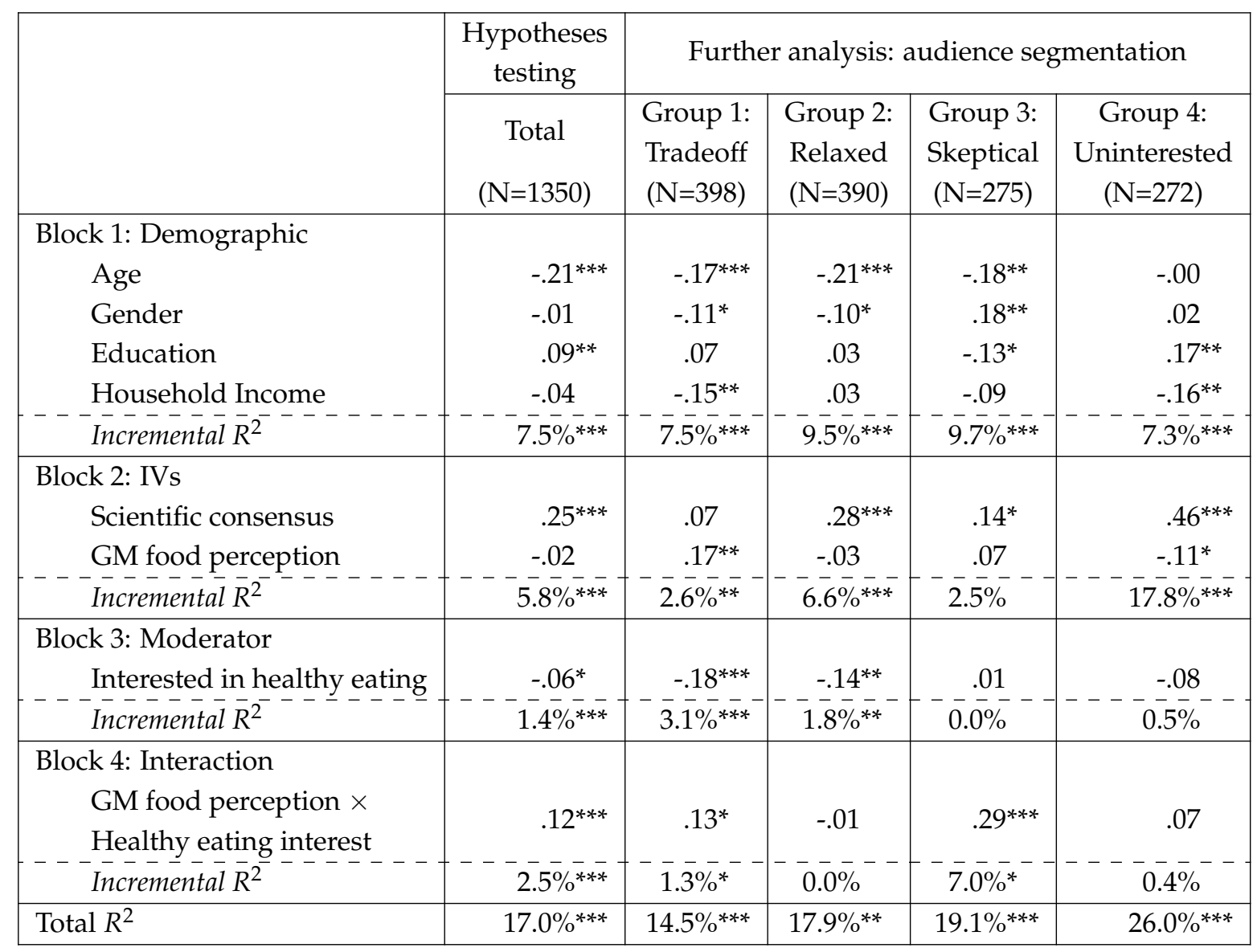

Note: Cell entries are final standardized regression coefficients for blocks 1, 2, and 3 in which all independent variables have been included while cell entries for block 4 are before-entry standardized regression coefficients that control for variables entered in the previous block but not for interactions entered in the same block.

a) The variable gender was coded $0=$ male, $1=$ female; b) ${ }^{*} \mathrm{p}<.05 ;{ }^{* *} \mathrm{p}<.01 ; * * * \mathrm{p}<.001$.

served a moderating role in this relationship (H5: $\beta=.12, \mathrm{p}<.001)$. Thus, $\mathrm{H} 5$ was supported. More specifically, the interaction reveals that among individuals who were more interested in healthy eating, those who have more favorable perception of GM foods were much more likely to consume GM food than those who perceive less benefit. Among the group of individuals who were less interested in healthy eating, however, there was weakened difference in the effect of perception on GM food consumption.

\section{Further analyses (RQs): audience segmentation}

This study also attempts to answer whether different groups of people choose different strategies when making decisions about controversial GM food (RQ1\&2). Given the fact that there is some controversy over the benefits and risks of GM foods and members of the public continue to express concerns about the potential risks of it [Bawa and Anilakumar, 2013; Turker et al., 2013], this study chose Gaskell et al.'s categorization [2004]. 
Our data showed that about $29 \%$ of respondents use rational decision-making approach in the process of food decision (Tradeoff: $N=415$ ), while almost half of the samples rely on either risk or benefit perception as rules of thumb strategies (Relaxed: $\mathrm{N}=407$; Skeptical: $\mathrm{N}=300)$. About $21 \%$ of respondents (Uninterested: $\mathrm{N}=304$ ), however, seem to be used neither risk nor benefit perception as decisive rule when making decisions.

As shown in Figure 3, those in the tradeoff $(\mathrm{M}=2.68, \mathrm{SD}=.86)$ or relaxed cell $(\mathrm{M}=2.75, \mathrm{SD}=.82)$ seemed to consume GM foods more compared to those in the skeptical $(\mathrm{M}=2.41, \mathrm{SD}=.79)$ or uninterested cell $(\mathrm{M}=1.81, \mathrm{SD}=.81):(F(3,1285)=83.62$, $\left.\eta_{p}^{2}=.16, \mathrm{p}<.001\right)$.

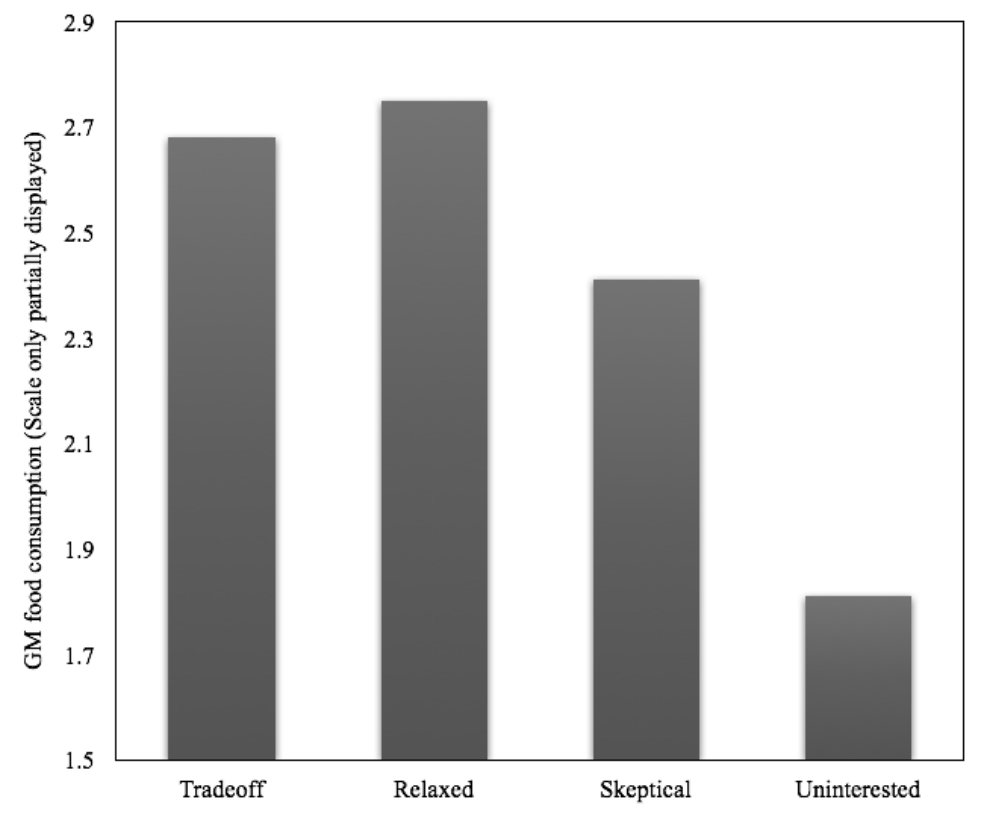

Figure 3. GM foods consumption by different groups based on levels of benefit/risk perceptions.

To explore our hypotheses in more depth, this study tests, depending on their benefit and risk perception, if people rely on different degree of factors to make their own food consumption decisions. As shown in Table 2, in prediction of GM foods consumption, this study found the main effect of scientific consensus about GM foods safety among the people in the relaxed $(\beta=.28, p<.001)$, skeptical $(\beta=.14$, $\mathrm{p}<.01)$ and uninterested $(\beta=.46, \mathrm{p}<.001)$ groups. However, we found no significant effect of scientific consensus among the tradeoff group $(\beta=.07, p=n . s$.). On the contrary, the current study found the main effect of favorable perception of GM foods on their consumption among the people in the tradeoff group $(\beta=.17, p<.01)$. But, we found no significant effect of GM food perception among the relaxed $(\beta=-.03, p=n . s$.$) and skeptical (\beta=.07, p=$ n.s. $)$ groups.

Furthermore, this study found the interaction effect of favorable perception and healthy eating interests on GM food consumption decision in the tradeoff group $(\beta=.13, p<.05)$ and skeptical group $(\beta=.29, \mathrm{p}<.001)$ while there was no same interaction effect found in other groups. The interactions both in the tradeoff and skeptical groups reveal that among individuals who were more interested in healthy eating, those who have a more favorable perception of GM foods were 
much more likely to consume GM food than those who perceive less benefit. (see, Figure 4). Among the group of individuals who were less interested in healthy eating, however, there was attenuated difference in the effect of favorable perception on GM food consumption.

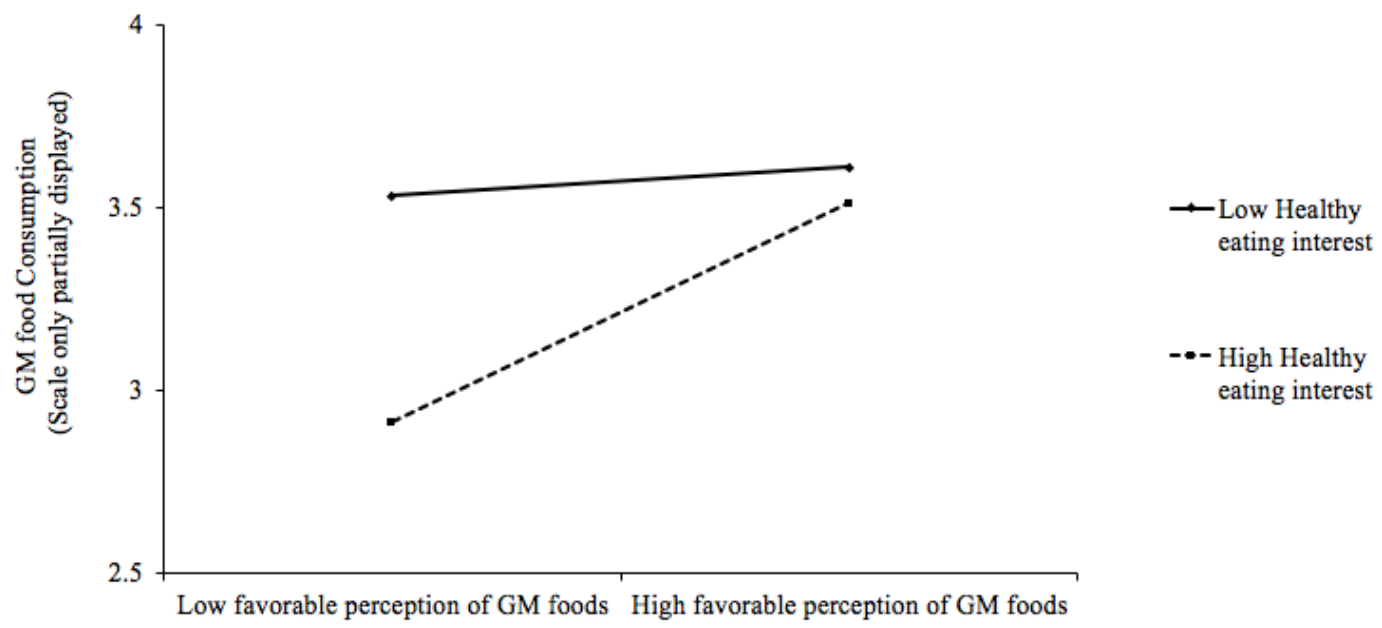

Figure 4. Interaction effect between GM food perception and interested in healthy eating on GM foods consumption among the tradeoff group.

People seem to be more interested in their health today than in the past and therefore tend to follow healthier lifestyles and eat healthier food. However, people are still confused about what foods to eat or to avoid [Food Insight, 2017], so they hesitate when making healthy food decisions. When it comes to controversial issues such as GM foods, people seem to be stuck on making decisions due to the issue's complexity even though much of the food in supermarkets contains at least some genetically modified ingredients [Funk and Kennedy, 2016a]. Hence, we are interested in understanding how people form their attitudes toward controversial but less known GM foods.

\section{Main findings of this study}

This study seeks to provide further insight into how laypeople perceive biotechnological food products and how their perceptions affect consumption decisions on the issue. Our results empirically find that explanatory precedence factors such as perceived scientific consensus, the public's views on scientists, GM food perceptions, and healthy eating interests impact GM food consumption decisions. Specifically, our study found that perceived scientific consensus about GM food safety directly affects favorable GM food perceptions (H1) and GM food consumption decisions (H2). In particular, people with higher levels of deference to scientific authority showed a stronger correlation between scientific consensus and favorable perception of GM foods compared to people with lower levels of deference to scientific authority (H3). Furthermore, our results indicate that individual's healthy eating interests moderate the relationship between GM food perceptions and consumption (H5). Remarkably, we found that people choose different strategies when making decisions about controversial food science (RQs). When we divided our samples into four groups based on participants' perceptions 
regarding the benefits and risks of the issue, our data revealed that in the relaxed, skeptical group and the uninterested group, the perceived scientific consensus had greater effects on food consumption decisions than favorable perception. However, in the tradeoff group, favorable perception had more substantial effects on food consumption decisions.

Contrary to our expectations, our data does not provide any statistical evidence to show a direct correlation between favorable GM food perceptions and consumption decisions (H4). In other words, to some participants, a positive perception of GM foods does not seem to be sufficient to motivate them to consume the food. This is probably because people's acceptance of GM food is conditioned by the results of the perceived benefit-risk assessment. As previously discussed, when it comes to GM food decisions, some people make their decisions after consciously calculating the potential risks and benefits while others use only one attribute, such as either risk or benefit perception [Kim, Kim and Besley, 2013; Gaskell et al., 2004]. That is, if the perceived risks of GM foods outweigh the perceived benefits of GM foods, some people would decide not to consume GM foods even if they still have a positive attitude toward GM foods. Another factor affecting consumers' decisions could be price sensitivity. Besides the influence of GM food perceptions, research shows that consumers who were sensitive to food prices were more likely to buy GM foods [Delmond et al., 2018]. Since this study uses secondary data, despite its expected theoretical and practical contributions for understanding GM food decisions, we cannot demonstrate if perceived behavior control (PBC) such as price sensitivity plays a role in people's decisions. However, we believe that price might impact individuals' GM food consumption decisions, because GM food is usually priced lower than its non-GM counterparts in the market [Ganiere, Chern and Hahn, 2006]. Therefore, we propose that future research exploring the influence of potential PBC can help people involved in food science better understand how these issues impact science, health, and policy making.

\section{Contribution to knowledge of this study}

We believe that this study offers reliable findings and insight concerning public attitudes towards scientific communities and perceptions about biotechnological food in terms of predicting GM food consumption decisions. First, the findings of this study indicate that it is important to promote people's interests in healthy eating because it directly affects their healthy food decisions. It is encouraging that most Americans already understand the benefits of healthy eating habits [Kapsak et al., 2011], and they seek health benefits from making better food decisions.

More importantly, since GM food has health and nutrition but also scientific implications, the current study determines the main and moderating role of the public's views on scientists in predicting GM food consumption decisions. Although public perception considers GM food unhealthy [Turker et al., 2013], scientists have claimed that GM foods are safe to eat [Funk, Rainie and Page, 2015]. Hence, this study assumes that people are less likely to avoid GM foods if they hold favorable views of scientists. In detail, the study revisits the significant role of scientific consensus in science, health, and nutrition communication. The current study finds that perceived scientific consensus not only affects laypeople's perception of the GM technology, it also affects their decisions about it. It is not 
surprising that those who perceived high levels of scientific consensus about food safety had positive relationships with GM food consumption. Laypeople tend to support more controversial issues if they perceive higher levels of scientific consensus on the issue, because it could reduce their perception about scientific uncertainty [Chinn, Lane and Hart, 2018]. Furthermore, our data also shows that favorable perception of GM foods are associated with people's food decisions about consuming GM foods. This finding is in line with previous studies. Gaskell et al. [2004] proposed that perceived benefits might be more important than perceived risks when it comes to decisions about GM food. However, our data showed that the influence of scientific consensus and a favorable perception varies from person to person. For instance, we identified some suggestive evidence that views on the scientific community moderate the effect of scientific consensus and perception of the GM foods. Also, the influence of scientific consensus is negated among people who perceive higher benefits and risks of GM foods.

One of the most interesting findings of the current study is that people use different strategies in the process of their GM food decisions depending on their benefit and risk perception levels. Perhaps this occurs because people hold different rules about how they make decisions. Controversies surrounding the safety of GM foods have emerged repeatedly between publics and scientists. Our findings suggest that segmenting audiences is a useful way to improve people's understanding of controversial biotechnology issues such as GM foods. In other words, segmenting publics for GM attitude and intention is meaningful in the practice. GM food campaigns can propose more tailored messages for specific groups of audiences. We hope that our study provides some practical implications to public health policy makers, scientists working on GM foods, and communication experts about health-science issues by suggesting the influential determinants of actual behaviors related to healthy diets.

\section{Limitations of the study}

The current study tries to interpret influences on public health behaviors without distortion. However, as with any study, limitations exist. First, researchers usually use multiple scales and combine questions to evaluate responses in cases involving the measurement of powerful and elaborate predictive variables. However, we used secondary data from the Pew Research Center for this study, which means that the data was not gathered for the specific purpose of this study. The current study relied on a single item to measure each critical variable, which may limit the construct validity and reliability. As such, the results may be limited. Furthermore, this study primarily explores the determinants of perceptions of GM foods and tests the causal relationship between public views on scientists, perceptions of certain foods, healthy eating interest, and actual GM food decision. However, all analyses are based on a cross-sectional survey. Therefore, it is difficult to confirm the causality between endogenous variables, so the findings should be interpreted with caution. With these considerations in mind, we suggest that follow-up research should be conducted to answer some of these unexplored facets. 
Interest in healthy eating has progressively surged in recent years, but it is still difficult to make food decisions. Thus, this study attempts to find some societal implications to identify ways to increase the prevalence of healthy food choices among the public. To gain a better understanding of how people make food decisions, the current study examines what influential factors affect people's food perceptions and actual food consumption. To test the hypotheses and research questions, this study uses a controversial food item - genetically modified food - as a context of inquiry.

Based on our findings, we suggest that public views on scientists (e.g., scientific consensus and deference to scientific authority) and perception of certain food technologies could play vital roles as persuasive strategies in science, health and nutrition communication. However, communicators and practitioners should also consider appealing to vulnerable audiences with persuasive communication. When it comes to health and science issues, public understanding and public perception on controversial issues could be easily changed if existing scientific findings are challenged with new information that overturns previous beliefs [American Association for the Advancement of Science, 1990]. In addition, as found in existing research [e.g. Chinn, Lane and Hart, 2018], we also suggest that scientific communicators and practitioners carefully explore and develop different consensus messages to persuade different audiences.

\section{References}

Ajzen, I. (1985). 'From intentions to actions: a theory of planned behavior'. In: Action control. Berlin, Heidelberg, Germany: Springer, pp. 11-39. https://doi.org/10.1007/978-3-642-69746-3_2.

- (1991). 'The theory of planned behavior'. Organizational Behavior and Human Decision Processes 50 (2), pp. 179-211. https://doi.org/10.1016/0749-5978(91)90020-T.

- (2015). 'The theory of planned behaviour is alive and well and not ready to retire: a commentary on Sniehotta, Presseau and Araújo-Soares'. Health Psychology Review 9 (2), pp. 131-137. https://doi.org/10.1080/17437199.2014.883474.

Akin, H., Yeo, S. K., Wirz, C. D., Scheufele, D. A., Brossard, D., Xenos, M. A. and Corley, E. A. (2018). 'Are attitudes toward labeling nano products linked to attitudes toward GMO? Exploring a potential 'spillover' effect for attitudes toward controversial technologies'. Journal of Responsible Innovation 6 (1), pp. 50-74. https://doi.org/10.1080/23299460.2018.1495026.

American Academy of Arts \& Sciences (2018). Perceptions of science in America. U.S.A.

URL: https://www . amacad .org/multimedia/pdfs/publications/researchpap ersmonographs/PFoS-Perceptions/PFoS-Perceptions-Science-America.pdf.

American Association for the Advancement of Science (1990). Science for all Americans.

URL: http://www .project2061.org/publications/sfaa/online/sfaatoc.htm (visited on 30th March 2019).

Barrows, G., Sexton, S. and Zilberman, D. (2014). 'Agricultural biotechnology: the promise and prospects of genetically modified crops'. Journal of Economic Perspectives 28 (1), pp. 99-120. https://doi.org/10.1257/jep.28.1.99. 
Barry, C. L., Jarlenski, M., Grob, R., Schlesinger, M. and Gollust, S. E. (2011). 'News media framing of childhood obesity in the United States from 2000 to 2009 '. Pediatrics 128 (1), pp. 132-145. https://doi.org/10.1542/peds. 2010-3924.

Bawa, A. S. and Anilakumar, K. R. (2013). 'Genetically modified foods: safety, risks and public concerns - a review'. Journal of Food Science and Technology 50 (6), pp. 1035-1046. https://doi.org/10.1007/s13197-012-0899-1.

Besley, J. C. and Shanahan, J. (2005). 'Media attention and exposure in relation to support for agricultural biotechnology'. Science Communication 26 (4), pp. 347-367. https://doi .org/10.1177/1075547005275443.

Brossard, D. and Nisbet, M. C. (2007). 'Deference to Scientific Authority Among a Low Information Public: Understanding U.S. Opinion on Agricultural Biotechnology'. International Journal of Public Opinion Research 19 (1), pp. 24-52. https://doi.org/10.1093/ijpor/edl003.

Brossard, D., Scheufele, D. A., Kim, E. and Lewenstein, B. V. (2009). 'Religiosity as a perceptual filter: examining processes of opinion formation about nanotechnology'. Public Understanding of Science 18 (5), pp. 546-558. https://doi.org/10.1177/0963662507087304.

Cacciatore, M. A., Scheufele, D. A. and Corley, E. A. (2011). 'From enabling technology to applications: the evolution of risk perceptions about nanotechnology'. Public Understanding of Science 20 (3), pp. 385-404. https://doi.org/10.1177/0963662509347815.

Chinn, S., Lane, D. S. and Hart, P. S. (2018). 'In consensus we trust? Persuasive effects of scientific consensus communication'. Public Understanding of Science 27 (7), pp. 807-823. https://doi .org/10.1177/0963662518791094.

Cohen, J. and Cohen, P. (1983). Applied multiple regression/correlation analysis for the behavioral sciences. 2nd ed. Hillsdale, NJ, U.S.A.: Erlbaum.

Costa-Font, M., Gil, J. M. and Traill, W. B. (2008). 'Consumer acceptance, valuation of and attitudes towards genetically modified food: review and implications for food policy'. Food Policy 33 (2), pp. 99-111. https://doi.org/10.1016/j.foodpol.2007.07.002.

Critchley, C. R. (2008). 'Public opinion and trust in scientists: the role of the research context, and the perceived motivation of stem cell researchers'. Public Understanding of Science 17 (3), pp. 309-327. https://doi.org/10.1177/0963662506070162. PMID: 19069082.

Delmond, A. R., McCluskey, J. J., Yormirzoev, M. and Rogova, M. A. (2018). 'Russian consumer willingness to pay for genetically modified food'. Food Policy 78, pp. 91-100. https://doi.org/10.1016/j.foodpol.2018.02.004.

Dixon, G. (2016). 'Applying the Gateway Belief Model to Genetically Modified Food Perceptions: New Insights and Additional Questions'. Journal of Communication 66 (6), pp. 888-908. https://doi.org/10.1111/jcom.12260.

Dixon, G. N., McKeever, B. W., Holton, A. E., Clarke, C. and Eosco, G. (2015). 'The power of a picture: overcoming scientific misinformation by communicating weight-of-evidence information with visual exemplars'. Journal of Communication 65 (4), pp. 639-659. https://doi.org/10.1111/jcom. 12159.

Domingo, J. L. and Giné Bordonaba, J. (2011). 'A literature review on the safety assessment of genetically modified plants'. Environment International 37 (4), pp. 734-742. https://doi.org/10.1016/j.envint.2011.01.003.

Dunwoody, S. and Neuwirth, K. (1991). 'Coming to terms with the impact of communication on scientific and technological risk judgments'. In: Risky business. Ed. by L. Wilkins and P. Patterson. New York, NY, U.S.A.: Greenwood, pp. 11-30. 
Dutta-Bergman, M. J. (2006). 'A formative approach to strategic message targeting through soap operas: using selective processing theories'. Health Communication 19 (1), pp. 11-18. https://doi.org/10.1207/s15327027hc1901_2.

Eagly, A. H. and Chaiken, S. (1993). The Psychology of Attitudes. Orlando, FL, U.S.A.: Harcourt Brace Jovanovich College Publishers.

Eden, S. (2011). 'Food labels as boundary objects: how consumers make sense of organic and functional foods'. Public Understanding of Science 20 (2), pp. 179-194. https://doi.org/10.1177/0963662509336714.

Fiske, S. T. and Taylor, S. E. (1991). Social cognition. 2nd ed. New York, NY, U.S.A.: McGraw-Hill.

Flipse, S. M. and Osseweijer, P. (2013). 'Media attention to GM food cases: an innovation perspective'. Public Understanding of Science 22 (2), pp. 185-202. https://doi.org/10.1177/0963662512458631.

Food Insight (13th May 2017). A healthy perspective: understanding american food values. The international food information council foundation's 12th annual food \& health survey. URL: https : //foodinsight.org/2017-food-and-health -survey-a-healthy-perspective-understanding-american-food-values/.

Frewer, L., Lassen, J., Kettlitz, B., Scholderer, J., Beekman, V. and Berdal, K. G. (2004). 'Societal aspects of genetically modified foods'. Food and Chemical Toxicology 42 (7), pp. 1181-1193. https://doi.org/10.1016/j.fct.2004.02.002.

Funk, C. and Kennedy, B. (1st December 2016a). The new food fights: U.S. public divides over food science. URL: https://www. pewresearch.org/science/2016/12 /01/the-new-food-fights/.

Funk, C., Rainie, L. and Page, D. (1st July 2015). Americans, politics and science issues. URL: https://www . pewresearch.org/science/2015/07/01/americans-politi cs-and-science-issues/.

Funk, C. and Kennedy, B. (2016b). 'Public opinion about genetically modified foods and trust in scientists connected with these foods'. Pew Research Center: Internet E Technology. URL: http://www.pewinternet.org/2016/12/01/public-opinion -about-genetically-modified-foods-and-trust-in-scientists-connected -with-these-foods/.

Ganiere, P., Chern, W. S. and Hahn, D. (2006). 'A continuum of consumer attitudes toward genetically modified foods in the United States'. Journal of Agricultural and Resource Economics 31 (1), pp. 129-149. URL: https://www . jstor.org/stable/40987310.

Gaskell, G., Allum, N., Wagner, W., Kronberger, N., Torgersen, H., Hampel, J. and Bardes, J. (2004). 'GM foods and the misperception of risk perception'. Risk Analysis 24 (1), pp. 185-194. https://doi.org/10.1111/j.0272-4332.2004.00421.x.

Gil, J. (2000). 'Market segmentation and willingness to pay for organic products in Spain'. The International Food and Agribusiness Management Review 3 (2), pp. 207-226. https://doi .org/10.1016/s1096-7508(01)00040-4.

Hasimu, H., Marchesini, S. and Canavari, M. (2017). 'A concept mapping study on organic food consumers in Shanghai, China'. Appetite 108, pp. 191-202. https://doi.org/10.1016/j.appet.2016.09.019.

Hughner, R. S., McDonagh, P., Prothero, A., Shultz, C. J. and Stanton, J. (2007). 'Who are organic food consumers? A compilation and review of why people purchase organic food'. Journal of Consumer Behaviour 6 (2-3), pp. 94-110. https://doi.org/10.1002/cb.210. 
Iversen, A. C. and Kraft, P. (2006). 'Does socio-economic status and health consciousness influence how women respond to health related messages in media?' Health Education Research 21 (5), pp. 601-610.

https://doi.org/10.1093/her/cy1014.

Jensen, J. D. and Hurley, R. J. (2012). 'Conflicting stories about public scientific controversies: effects of news convergence and divergence on scientists' credibility'. Public Understanding of Science 21 (6), pp. 689-704. https://doi.org/10.1177/0963662510387759.

Kapsak, W. R., Rahavi, E. B., Childs, N. M. and White, C. (2011). 'Functional foods: consumer attitudes, perceptions and behaviors in a growing market'. Journal of the American Dietetic Association 111 (6), pp. 804-810. https://doi.org/10.1016/j.jada.2011.04.003.

Kikulwe, E. M., Wesseler, J. and Falck-Zepeda, J. (2011). 'Attitudes, perceptions and trust. Insights from a consumer survey regarding genetically modified banana in Uganda'. Appetite 57 (2), pp. 401-413. https://doi.org/10.1016/j.appet.2011.06.001.

Kim, J., Yeo, S. K., Brossard, D., Scheufele, D. A. and Xenos, M. A. (2014). 'Disentangling the influence of value predispositions and risk/benefit perceptions on support for nanotechnology among the american public'. Risk Analysis 34 (5), pp. 965-980. https://doi.org/10.1111/risa.12141.

Kim, S.-H. and Anne Willis, L. (2007). 'Talking about obesity: news framing of who is responsible for causing and fixing the problem'. Journal of Health Communication 12 (4), pp. 359-376. https://doi.org/10.1080/10810730701326051.

Kim, S.-H., Kim, J.-N. and Besley, J. C. (2013). ‘Pathways to support genetically modified (GM) foods in South Korea: deliberate reasoning, information shortcuts and the role of formal education'. Public Understanding of Science 22 (2), pp. 169-184. https://doi.org/10.1177/0963662512442308.

Knight, A. (2007). 'Intervening effects of knowledge, morality, trust and benefits on support for animal and plant biotechnology applications'. Risk Analysis 27 (6), pp. 1553-1563. https://doi.org/10.1111/j.1539-6924.2007.00988.x.

Lü, L. (2006). 'Chinese public understanding of the use of agricultural biotechnology - a case study from Zhejiang Province of China'. Journal of Zhejiang University Science B 7 (4), pp. 257-266. https://doi.org/10.1631/jzus.2006.b0257.

Maibach, E. W. and van der Linden, S. L. (2016). 'The importance of assessing and communicating scientific consensus'. Environmental Research Letters 11 (9), p. 091003. https://doi.org/10.1088/1748-9326/11/9/091003.

Marques, M. D., Critchley, C. R. and Walshe, J. (2015). 'Attitudes to genetically modified food over time: How trust in organizations and the media cycle predict support'. Public Understanding of Science 24 (5), pp. 601-618. https://doi.org/10.1177/0963662514542372. PMID: 25063421.

Miller, D. T. (2001). 'The norm of self-interest'. In: The next phase of business ethics: integrating psychology and ethics. Bingley, U.K.: Emerald Group Publishing Limited, pp. 193-210.

Niva, M. (2007). "All foods affect health': understandings of functional foods and healthy eating among health-oriented Finns'. Appetite 48 (3), pp. 384-393. https://doi.org/10.1016/j.appet.2006.10.006.

Popkin, S. L. (1994). The reasoning voter: communication and persuasion in presidential campaigns. 2nd ed. Chicago, IL, U.S.A.: University of Chicago Press. 
Rana, J. and Paul, J. (2017). 'Consumer behavior and purchase intention for organic food: a review and research agenda'. Journal of Retailing and Consumer Services 38, pp. 157-165. https://doi.org/10.1016/j. jretconser.2017.06.004.

Regan, D. T. and Fazio, R. (1977). 'On the consistency between attitudes and behavior: look to the method of attitude formation'. Journal of Experimental Social Psychology 13 (1), pp. 28-45. https://doi.org/10.1016/0022-1031(77)90011-7.

Shahbandeh, M. (2019). Percentage of genetically modified crops in the U.S. by type 1997, 2018 \& 2019. URL: https://www. statista.com/statistics/217108/level-of genetically-modified-crops-in-the-us/.

Siegrist, M. (2000). 'The Influence of Trust and Perceptions of Risks and Benefits on the Acceptance of Gene Technology'. Risk Analysis 20 (2), pp. 195-204. https://doi.org/10.1111/0272-4332.202020.

Slovic, P. (1987). 'Perception of risk'. Science 236 (4799), pp. 280-285. https://doi.org/10.1126/science.3563507.

Slovic, P. (1999). 'Trust, emotion, sex, politics and science: surveying the risk-assessment battlefield'. Risk Analysis 19 (4), pp. 689-701. https://doi.org/10.1111/j.1539-6924.1999.tb00439.x.

Slovic, P., Fischhoff, B. and Lichtenstein, S. (1982). 'Why study risk perception?' Risk Analysis 2 (2), pp. 83-93. https://doi.org/10.1111/j.1539-6924.1982.tb01369.x.

Turker, T., Kocak, N., Aydin, I., Istanbulluoglu, H., Yildiran, N., Turk, Y. and Kilic, S. (2013). 'Determination of knowledge, attitude, behavior about genetically modified organisms in nursing school students'. Gulhane Medical Journal 55 (4), p. 297. https: //doi.org/10.5455/gulhane. 33326.

United States Department of Agriculture (2016). Nutrients and health benefits. URL: https://www . choosemyplate.gov/vegetables-nutrients-health.

van der Linden, S. L., Clarke, C. E. and Maibach, E. W. (2015). 'Highlighting consensus among medical scientists increases public support for vaccines: evidence from a randomized experiment'. BMC Public Health 15 (1), p. 1207. https://doi.org/10.1186/s12889-015-2541-4.

van der Linden, S. L., Leiserowitz, A. A., Feinberg, G. D. and Maibach, E. W. (2015). 'The Scientific Consensus on Climate Change as a Gateway Belief: Experimental Evidence'. PLOS ONE 10 (2), e0118489. https://doi.org/10.1371/journal.pone.0118489.

van der Linden, S., Leiserowitz, A. and Maibach, E. (2019). 'The gateway belief model: a large-scale replication'. Journal of Environmental Psychology 62, pp. 49-58. https://doi.org/10.1016/j.jenvp. 2019.01.009.

Vandermoere, F., Blanchemanche, S., Bieberstein, A., Marette, S. and Roosen, J. (2011). 'The public understanding of nanotechnology in the food domain: the hidden role of views on science, technology and nature'. Public Understanding of Science 20 (2), pp. 195-206. https : //doi.org/10.1177/0963662509350139.

Wunderlich, S. and Gatto, K. A. (2015). 'Consumer perception of genetically modified organisms and sources of information'. Advances in Nutrition 6 (6), pp. 842-851. https://doi.org/10.3945/an.115.008870.

Yang, Y. T. and Chen, B. (2016). 'Governing GMOs in the U.S.A.: science, law and public health'. Journal of the Science of Food and Agriculture 96 (6), pp. 1851-1855. https://doi.org/10.1002/jsfa.7523. 
Jiyoun Kim. Dr. Kim earned her PhD at the University of Wisconsin-Madison. Her research is broadly concerned with science, health and risk communication. She is particularly interested in how we can harness the power of communication to design and deliver effective messaging to help the public have more meaningful conversations about science and health issues in order to help the public make more informed decisions. E-mail: jkimcomm@umd.edu.

Sumin Fang. Sumin Fang earned her B.A. in Journalism and M.A. in Communication Studies and Education. She is currently pursuing a Ph.D. in Communication with an emphasis in Public Relations. Her research interests include technology and health communication, organization-public relationship, and crisis communication. E-mail: suminfang1@gmail.com.

How to cite

Kim, J. and Fang, S. (2020). 'Decisions to choose genetically modified foods: how do people's perceptions of science and scientists affect their choices?'. JCOM 19 (02), A01. https:/ / doi.org/10.22323/2.19020201. 